\title{
HIERARCHICAL COPULAE IN CREDIT RISK MODELING
}

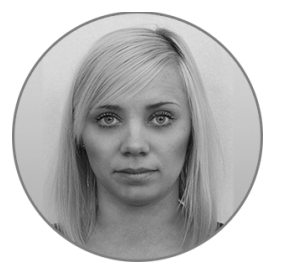

\author{
Kristina A. KAZAKOVA \\ Astrakhan State University, Astrakhan, Russian Federation \\ kristinakazakova0309@gmail.com \\ Corresponding author
}

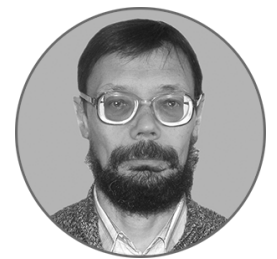

\section{Aleksandr G. KNYAZEV}

Astrakhan State University, Astrakhan, Russian Federation

agkniazev@mail.ru

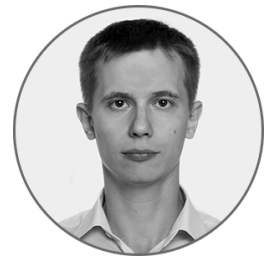

\section{Oleg A. LEPEKHIN}

Astrakhan State University, Astrakhan, Russian Federation okmb07@yandex.ru

\section{Article history:}

Received 28 April 2017

Received in revised form 15 May 2017

Accepted 9 June 2017

Translated 27 July 2017

Available online 15 September 2017

\section{JEL classification: C58, G17}

Keywords: bank reserve, credit risk, overdue loan debt, copula-based model, forecast

\begin{abstract}
Importance This research outlines an economic and mathematical model of the overdue loan debt. The model is based on copula functions allowing to simulate a non-Gaussian distribution of financial risks and credit risk, in particular.

Objectives The research models a joint distribution of overdue debt series in order to forecast the credit risk exposure. Relying upon the forecast, we intend to evaluate the efficiency of methods used to make provisions for possible losses and subsequently determine a reasonable approach to accruing the provision.

Methods We examine whether hierarchical copula models can be applied to build the joint distribution of overdue loan debt series in relation to banking institutions. It is considered as the basis for making further estimates of the overdue loan debt.

Results We build and evaluate a multivariate copula model of overdue loan debt with the hierarchical structure. Based on the modeled multivariate correlation, we forecast indicators of the overdue loan debt, which could be used as estimated provisions for credit losses. The estimated provisions turn to be sufficient for covering the real amount of overdue debt, being, in most cases, much less than that indicated in Regulation of the Central Bank of the Russian Federation № 254-П, On Rates of Provisions for Loan Losses.

, Conclusions and Relevance The multivariate copula model of the overdue loan debt can underlie effective risk management systems in credit institutions.
\end{abstract}

The editor-in-charge of this article was Irina M. Komarova

Authorized translation by Irina M. Komarova 
Currently, both academics and practitioners are involved into active debates on the issues of evaluating the level of banks' capital adequacy in case of unforeseen losses. Considering the financial and economic instability, the theory and practice of banking experience a growing need in systemic approaches to assessing and managing financial risks.

As part of their financial and business operations, bankers prefer to involve as little capital as possible, thus boosting a growth in assets and profitability. Banking supervisory bodies, by contrast, consider substantial amounts of capital as the main remedy against bankruptcy. Hence, there are a lot of speculations and ambivalence concerning the approach to assessing the capital adequacy. This is a quite justifiable point of view that bankruptcies in banking mainly stem from poor management. Therefore, well-managed banks are able to continue their operations smoothly even if their capital ratio is low. We shall mention the following paradox of generally accepted standards of bank supervisory authorities. Stating the importance of the capital adequacy assessment, those standards hardly ever regulate the management process in terms of risk exposures.

Trying to approximate international standards, Russia's banks perform relevant procedures to implement internal systems for capital adequacy assessment as enshrined in the Basel II Accord. Nowadays, Resolution of the Central Bank of the Russian Federation of March 26, 2004 № 254-П, On Rules of Credit Institutions for Making Provisions for Possible Losses from Loans, Outstanding Loans and Identical Debts, is still effective, being, to a certain extent, the first attempt to converge with provisions of the Basel II Accord. The methodology therein has some controversial aspects ${ }^{1}$. Their interpretation may undermine the efficiency of existing procedures used to make bank reserves for unforeseen loan losses, from perspectives of the reasonable use of financial resources.

${ }^{\dagger}$ For the source article, please refer to: Казакова К.А., Князев А.Г., Лепёхин О.А. Иерархические копулы в моделировании кредитного риска. Национальные интересы: приоритеты и безопасность. 2017. Т. 22. Вып. 6. С. 1032-1044. https://doi.org/10.24891/ni.13.6.1032

${ }^{1}$ Kazakova K.A., Knyazev A.G., Lepekhin O.A., Skobleva E.I. Assessment and Management of Banking Risks in the Global Community: Benefits and Challenges of Implementation of Basel Standards. Asian Social Science, 2015, vol. 11, no. 20, pp. 141-147. URL: http://dx.doi.org/10.5539/ass.v11n20p141
Committee on Banking Supervision of the Bank for International Settlements, however, constantly revises its strategies for the capital adequacy assessment, considering the internationalization of economic communities, modernization of the banking sector in line with inherent uncertainty. The use of copulae is one of the appropriate methods to risk assessment, according to the Committee's instructions ${ }^{2}$. Setting respective multivariate dependencies represents a toolkit that allows to model a non-Gaussian distribution of financial risks and default risk, in particular.

There are many researches into financial risks and credit risk, in particular, which opt for modeling based on copula functions as the methodological underpinning. For example, these are researches by Ya.V. Bologov [1], K.A. Kazakova ${ }^{3}$. Furthermore, we shall mention proceedings by D. Fantazzini, meaning not only theoretical principles of multivariate dependency modeling [2], but also practical applicability of copulae for assessing financial institutions' risks $[3,4]$.

The research examines whether hierarchical copula-based models can be used to construct joint distributions of overdue loan debt series, which will underlie further forecasts of overdue loan debts. We evaluate the proposed alternative to making reserves in terms of the reasonable use of financial resources, and determine whether it is effective for banks to quantify credit risks in their risk management.

We begin with exploring the copula theory and substantiating why we choose the copula-based model. Subsequently, we build and evaluate the model of overdue loan debt, estimating outstanding amounts of previous loans. We generate a joint distribution sample. At the final step, we perform a comparative analysis of the efficiency of the reserve made for credit losses.

Referring to the theory, it is noticeable that $C\left(u_{1}, u_{2}, \ldots, u_{n}\right)$ copula denotes the function of the joint

\footnotetext{
${ }^{2}$ Basel III: A Global Regulatory Framework for More Resilient Banks and Banking Systems. Basel Committee on Banking Supervision, 2010. URL: http://bis.org/publ/bcbs189_dec2010.pdf

${ }^{3}$ Kazakova K.A., Knyazev A.G., Lepekhin O.A. [Optimum volume of bank reserve: Forecasting of overdue credit indebtedness using copula models]. Vestnik NGU. Seriya Sotsial'no-ekonomicheskie nauki = Vestnik NSU. Series: Social and Economics Sciences, 2015, vol. 15, iss. 4. (In Russ.)
} 
distribution of $n$-random variables that are evenly dispersed along the segment [0; 1]. Multivariate joint distributions are modeled using copula in accordance with the Sklar theorem [5]. As stated therein, any multivariate distribution can be presented as a set of partial functions of distribution and copula, which shapes the nature of their dependency.

Assume that $H$ is an $n$-function of the probability distribution, $F_{i}, \ldots, F_{n}$ are respective partial functions of a distribution of components. In this case, we can suppose the existence of C-copula, resulting in the following equation:

$$
H(x 1, \ldots, x n)=C(F 1(x 1), \ldots F n(x n)) .
$$

It is worth mentioning that the copula has a single definition, if all univariate functions of the distribution are continuous.

Hierarchical Archimedean copulae prevail among those ones used to model joint distributions of financial variables. It leads due to the simplicity of analytical expression of a respective family of copulae, on the one hand, and their ability to model heavy tailed distributions, on the other hand. Archimedean copulae include several well-known one-parameter copula families, i.e. the Frank copula, Gumbel-Hougaard copula, Clayton copula, etc. This research employs the Clayton copula. In case of two variables, it is expressed with the following formula [5]:

$$
\begin{aligned}
& C_{a}(u, v)=\max \left\{\left(u^{-a}+v^{-a}-1\right)^{1 /-a}, 0\right\} ; \\
& a \geq-1, a \neq 0,
\end{aligned}
$$

where $a$ is a parameter of the Clayton pair copula;

$u, v$ are random variables.

We choose the Clayton copula since this multivariate distribution function models the dependency among random variables, and has the left lower tail.

It is noteworthy that there are various measures to gauge the dependency of random variables. The Kendall rank correlation coefficient is of special significance for the copula theory, since it is closely related to parameters of copulae. In the Clayton pair copula, the following formula expresses the dependency of a copula parameter on the correlation coefficient [5]:

$$
a=\frac{2(1-\tau)}{\tau}
$$

where $a$ is a parameter of the Clayton pair copula;

$\tau$ is a coefficient of the Kendall rank correlation.

For purposes of this research, correlation coefficients are positive for all pairs of random variables, thus making parameters of copula positive too. Hence, the formula of the Clayton copula gets much simpler:

$$
C(u, v)=\left(u^{-\alpha}+v^{-\alpha}-1\right)^{-1 / \alpha}, a>0
$$

The Archimedean copula has a limited use for modeling multivariate dependency $(n>2)$ due to its symmetry, i.e. multivariate Archimedean copulae are invariant to any rearrangement of variables. Contemporary scholarly literature provides various methods for tackling this difficulty. The main suggestion is to construct multivariate models based on pair copulae. Thus, branching copulae, or vine-copulae, are one of possible combinations of pair copulae. Reading through multiple papers on vine-copulae, for purposes of this research, we highlight several foreign publications $[6,7]$, paper by A.I. Travkin [8], and a training course by S.A. Aivazyan ${ }^{4}$.

In this research, we attempt to adhere to another method based on pair Archimedean copulae to build multivariate models. This type of copulae is called hierarchical dependency. Such dependency is reviewed in proceedings referred in the references ${ }^{5}$ [9-11].

Scrutinizing the modeling process, we shall note that hierarchical copulae are built on a step-by-step basis. At each step, the pair copula $C(u, v)$ is modeled, where $u$ and $v$ represent pair copulae or random variables. Constituent blocks of a respective construction shall meet certain conditions to create a copula. Hierarchical copulae will ingrain only pair copula from the same family, and the Clayton pair copulae, in particular. Furthermore, we will use only those copulae that have positive properties. In this case, we have the following conditions for preserving a copula-based structure. Assume that $C(u, v), C_{1}\left(u_{1}, v_{1}\right), C_{2}\left(u_{2}, v_{2}\right)$ are the Clayton pair copulae with parameters $a_{1} a_{1}, a_{2}$ respectively, then

\footnotetext{
${ }^{4}$ Aivazyan S.A., Fantazzini D. Ekonometrika-2: prodvinutyi kurs s prilozheniyami $v$ finansakh [Econometrics 2: An advanced course with the supplement on finance]. Moscow, INFRA-M Publ., 2014, 944 p.

${ }^{5}$ Puzanova N. A Hierarchical Archimedean Copula for Portfolio Credit Risk Modeling. Discussion Paper Series 2: Banking and Financial Studies 2011, 14. Deutsche Bundesbank, Research Centre, 32 p.
} 
the function $C\left(C_{1}\left(u_{1}, v_{1}\right), C_{2}\left(u_{2}, v_{2}\right)\right)$ defines a copula with four variables, provided that $a \leq \min \left(a_{1}, a_{2}\right)$ [11].

Choosing the hierarchical structure of dependency, which merges pair copulae into a multivariate model, constitutes the most critical aspect in designing hierarchical copulae. There are various approaches to this issue [4]. In this research, copulae are constructed in the following manner. A pair of variables with the highest Kendall rank correlation coefficient will be combined with a pair copula at each step. Variables can be represented with both source random values and values of pair copulae built at the previous steps.

It is reasonable to describe the data used in this research, and their primary processing. We use monthly data on general overdue loan debts and the general amount of the credit portfolio, both denominated in thousand RUB and pertaining to seven banking institutions of Russia, such as Alfa Bank $(A L P)$, VTB 24 (VTB), Promsvyazbank (PSB), Petrokommerz Bank (PKB), Khanty-Mansiiskii Bank $(H M B)$, Sobinbank (SIB), Novosibirsk Municipal Bank (NSB). We obtain all data from official financial statements of the banks as provided at the website of the Central Bank of Russia. It is worth mentioning that the sample of the above banks were generated as part of the prior research, being the outcome of the cluster and factor analysis of the banking system ${ }^{6}$. In the research, the timing interval was determined randomly, lasting from February 1, 2008, through October 1, 2013, since this research is, mainly, of methodological nature.

Initially, source data were processed by reviewing absolute values of overdue loan debt to relative figures. It resulted in time series that is a percentage of overdue amount from respective receivables in the general loan portfolio of each bank. Subsequently, each time series was centered and rated so to align the dynamism of the data.

Referring to model design and evaluation procedures, we should note that normal distributions are usually applied to model univariate distributions. However, normal distribution does not prove to be appropriate for all time series. Addressing the value of

\footnotetext{
${ }^{6}$ Skobeleva E.I., Knyazev A.G., Lepekhin O.A., Kazakova K.A. [Dynamic analysis of the segmentation of Russian banking sector]. Sovremennye problemy nauki i obrazovaniya, 2014, no. 6. (In Russ.) URL: http://scienceeducation.ru/120-16784
}

the probability that critical bounds of the KolmogorovSmirnov statistic will be exceeded for normal distributions, as given in Table 1, we can state that the hypothesis of normal distributions deviates for three series, considering the significance point of 0.05 . That is why the Student asymmetrical distribution was used to model univariate distributions. The Student asymmetrical distribution is expressed with the following formula [12]:

$$
d(z ; \lambda ; \eta)=\left\{\begin{array}{l}
b c\left(1+\frac{1}{\eta-2} \cdot\left(\frac{b z+a}{1-\lambda}\right)^{2}\right)^{\frac{-\eta+1}{z}}, z<-a / b \\
b c\left(1+\frac{1}{\eta-2} \cdot\left(\frac{b z+a}{1+\lambda}\right)^{2}\right)^{\frac{-\eta+1}{z}}, z \geqslant-a / b
\end{array}\right.
$$

where $a=4 c \lambda\left(\frac{\eta-2}{\eta-1}\right)$ ；

$$
\begin{aligned}
& b=\sqrt{1+3 \lambda^{2}-a^{2}} ; \\
& c=\frac{\Gamma\left(\frac{\eta+1}{2}\right)}{\sqrt{\pi(\eta-2) \Gamma\left(\frac{\eta}{2}\right)}} ;
\end{aligned}
$$

$\eta$ is the number of degrees of freedom (tail parameter);

$\lambda$ is the asymmetry parameter;

$\Gamma(x)$ is the gamma-function;

$z$ is an analyzable random value.

Based on the assessed traits of univariate distributions presented in Table 1, the hypothesis of the Student asymmetrical distribution does not evidently deviate for all series totally. In this respect, it is sensible to spotlight a significant asymmetry seen in all the series. Incidentally, the Clayton copula was chosen upon the analysis of joint spread in series of variables. A graphic analysis allows to trace the left lower tail, while the right upper tail is not palpable. As we mention, the Clayton copula is the best tool to model such dependencies.

It is worth mentioning that, in this research, we intend to derive parameters of copulae using the Bayesian method. First, the prior distribution should be determined. In this case, values of the parameter are sampled through the method of moments, and precisely the method for inversion of the Kendall correlation coefficient on the basis of the formula (3). 
Fig. 1 depicts the histogram of the primary sample of the parameter values.

This histogram lets us assume that the parameter of the copula has the gamma-distribution. Moreover, the sample also unveils other parameters of the gamma-distribution, such as the parameter of scale $r=0.457572$ and form $s=1.164896$. This assumption can be verified with the One-sample KolmogorovSmirnov test (data ACL D $=0,1162$, $p$-value $=0.9085$ ). As the test shows, the hypothesis on the gamma-distribution does not deviate in this case.

To make Bayesian estimates of the parameters, we apply the Metropolis-Hastings algorithm through a random walk. To put this method in practice, we devise an algorithm in the $R$ program environment presented in Appendix 1 hereto. Table 2 includes Bayesian estimates of source data parameters. In addition to the estimates of copulae, this table reflects model values of the Kendall correlation coefficient, which can be compared with sampled values of the coefficient. Table 3 contains the correlation matrix of source data.

As a subsequent step of the research, we shape the hierarchical structure and estimating parameters of hierarchical copulae. The following denotations will be reasonable to introduce: $u_{1}, u_{2}, u_{3}, u_{4}, u_{5}, u_{6}, u_{7}$ for univariate functions of a distribution of variables $A L P$, $V T B, P S B, P K B, K M B, S I B, N M B$ respectively. The Kendall correlation coefficients are the same as for initial variables. While determining the said structure of the copula, it is necessary to choose the pair $A L P, S I B$, that has the highest correlation coefficient. Therefore, the joint distribution function (hereinafter referred to as $\left.u_{16}\right)$ is based on a first-order approximation. As the second step, it is necessary likewise to generate a new correlation matrix, with its outcome given in Table 4.

Being the largest element in the matrix, the correlation coefficient matches the pair $u_{16}, u_{3}$. Thus, the following step is to estimate the parameter of this copula, which equals 3.095. Next we construct a relevant function of a joint distribution, which is denoted as $u_{(16) 3}$. After that, we reiterate the procedure for generating a new correlation matrix, and the process reoccurs. Being the product of the algorithm, the hierarchical structure is presented in Fig. 2.
Analyzing the outcome, it is remarkable that the estimated parameter of the last copula is a sequence higher than that indicated in the respective table, being equal to 0.8318202 . However, this estimate contravenes the condition for preserving the copula structure. In this respect, this estimate is accepted to be the lowest of all assessed components (Table 5).

The formula below demonstrates an explicit expression of the relevant copula-based model consisting of seven variables:

$$
\begin{aligned}
& C\left(u_{1}, u_{2}, u_{3}, u_{4}, u_{5}, u_{6}, u_{7},\right)= \\
& =\left(\left(\left(\left(u_{1}^{-\alpha_{1}}+u_{6}^{-\alpha_{1}}-1\right)^{\alpha_{2} / \alpha_{1}}+u_{3}^{-\alpha_{2}}-1\right)^{\alpha_{3} / \alpha_{2}}+u_{4}^{-\alpha_{3}}-1\right)^{\alpha_{4} / \alpha_{3}}+\right. \\
& \left.+u_{5}^{-\alpha_{4}}+\left(u_{2}^{-\alpha_{5}}+u_{7}^{-\alpha_{5}}-1\right)^{\alpha_{4} / \alpha_{5}}-2\right)^{-1 / \alpha_{4}} .
\end{aligned}
$$

Finally, we generate a sample of a joint distribution and forecast overdue accounts payable. It is sensible to apply the acceptance-rejection method to generate a joint distribution sample. The method implies the density of a joint distribution, but it is problematic to assess for the joint distribution function with respect to all seven variables. A step-by-step acceptance-rejection method can be used to simplify the task. First, we make a sample of seven independent random variables, with each of them having the Student asymmetrical distribution with parameters indicated in Table 1. Second, we select only those observations with the first and sixth variable having a joint distribution expressed through the Clayton copula with the parameter $a_{1}$ (Table 5). Afterwards we glean the sample for those observations, where the function of a joint distribution of the first and sixth variables and the third variable have a joint distribution expressed through the Clayton copula with the parameter $a_{2}$. The respective process continues as per the hierarchical model scheme. This process should be coupled with the assessment of a constant limiting the density of the respective pair copula [13]. The constant can be represented with the maximum density of the respective copula in the sample.

Summarizing the aforementioned, we shall point out six steps to be performed in order to combine source variables into a multivariate model. The sample size shrinks significantly at each step. Initially, we generate a sample of seven independent variables that contains 100,000 observations. Afterwards we select from one to three observations from a joint distribution expressed 
through a hierarchical model. Hence, reiterating this process as needed, we finally obtain a sample of 100 observations from joint distributions.

Table 6 includes the correlation matrix of the generated sample. The sample is, definitely, very different from the correlation matrix of the source sample, with significant moments of the hierarchical structure dependency remaining unchanged. Like in the source sample, the highest correlation coefficient is a coefficient between the first and sixth variables.

Based on the generated sample, we assess a bank reserve for unforeseen loan losses. It is noticeable that the reserve can be measured with two methods. For example, each variable can be sorted in descending order. Using the sixth variant, we can determine the upper bound of the unilateral confidence interval of 95 percent with respect to the amount of overdue accounts payable, which can be considered as the necessary volume of the respective reserve. It is also possible to arrange the entire sample of seven variables as values of the sample function of the distribution descend. As before, it is necessary to select the sixth observation and consider it as the upper bound of a 95-percent confidence zone. Table 7 indicates advisable amounts of provisions and real figures of overdue accounts payable.

Reviewing the forecast results, we can make the following conclusions. Advisable amounts of reserves seem to be adequate and reasonable. Forecasted estimates provide a sufficient understanding of overdue accounts payable as they are. However, when estimates were compared with real reserves, the forecast proved to be more precise than the first forecast made by aligning the sample of seven variables as values of the sample function of the distribution descended.

As a conclusion, the following aspects should be highlighted. The approach and subsequent forecasting - we propose in this research to model overdue accounts payable - constitute an alternative to the existing methodology used to assess a provision for possible loan losses. This alternative approach reinforces the sustainability of a financial institution and melds the efficiency and reasonableness any bank needs in its strategic management. As demonstrated in this research, the copula-based hierarchical model, to a certain extent, can be used as one of the available methods to quantify the credit risk in banking risk management.

Table 1

Univariate distribution parameters

\begin{tabular}{lllll}
\hline Variable & P norm & Eta & Lambda & Past \\
\hline$A L F$ & 0.00127 & 4 & 0.99 & 0.3552 \\
\hline$V T B$ & 0.06783 & 22 & -0.75 & 0.6428 \\
\hline$P S B$ & 0.1663 & 22 & 0.31 & 0.59948 \\
\hline$P K B$ & 0.4115 & 22 & -0.29 & 0.7526 \\
\hline$H M B$ & 0.4764 & 22 & 0.71 & 0.47721 \\
\hline$S I B$ & 0.0208 & 22 & 0.5 & 0.29263 \\
\hline$N S B$ & 0.00119 & 4.8 & -0.47 & 0.08122 \\
\hline
\end{tabular}

Note. $P$ norm, $P$ ast are the probability of random values exceeding critical statistics, Eta, Lambda are assessed parameters of the asymmetrical distribution for overdue debt series.

Source:Authoring 
Table 2

Bayesian estimates of pair-copula parameters

\begin{tabular}{lll}
\hline Variable & $\boldsymbol{A}$ & Tau \\
\hline$A L P / P S B$ & 3.0465 & 0.6037 \\
\hline$A L P / N T B$ & 0.3975 & 0.1658 \\
\hline PKB/ALP & 1.4556 & 0.4212 \\
\hline$H M B / A L P$ & 0.4013 & 0.1671 \\
\hline$S I B / A L P$ & 4.8416 & 0.7077 \\
\hline NSB/ALP & 0.5413 & 0.213 \\
\hline$P S B / N T B$ & 1.1382 & 0.3627 \\
\hline$P K B / N T B$ & 2.2616 & 0.5307 \\
\hline$H M B N T B$ & 1.7164 & 0.4618 \\
\hline$S I B / N T B$ & 0.6205 & 0.2368 \\
\hline$N S B N T B$ & 3.7974 & 0.655 \\
\hline$P K B / P S B$ & 3.6767 & 0.6477 \\
\hline$H M B / P S B$ & 0.9068 & 0.312 \\
\hline$S I B / P S B$ & 4.575 & 0.6958 \\
\hline$N S B / P S B$ & 1.3609 & 0.4049 \\
\hline$H M B / P K B$ & 1.5520 & 0.4369 \\
\hline$S I B / P K B$ & 2.4742 & 0.553 \\
\hline$N S B / P K B$ & 0.8564 & 0.2998 \\
\hline$S I B / H M B$ & 0.6496 & 0.2452 \\
\hline$N S B / H M B$ & 2.0652 & 0.508 \\
\hline
\end{tabular}

Note. $A$ is a Bayesian estimate of parameters for pairs of initial series of overdue debts, Tau is a model value of the Kendall correlation coefficient.

Source: Authoring

Table 3

The correlation matrix of initial variables

\begin{tabular}{lllllll}
\hline Variable & $\boldsymbol{A L P}$ & $\boldsymbol{V T \boldsymbol { B }}$ & $\boldsymbol{P S B}$ & $\boldsymbol{P K \boldsymbol { B }}$ & $\boldsymbol{H M B}$ & $\boldsymbol{S} \boldsymbol{B}$ \\
\hline VTB & 0.20 & 1 & $\ldots$ & $\ldots$ & $\ldots$ & $\ldots$ \\
\hline PSB & 0.7 & 0.42 & 1 & $\ldots$ & $\ldots$ & $\ldots$ \\
\hline PKB & 0.55 & 0.54 & 0.74 & 1 & $\ldots$ & $\ldots$ \\
\hline HMB & 0.05 & 0.46 & 0.26 & 0.39 & 1 & $\ldots$ \\
\hline SIB & 0.83 & 0.25 & 0.76 & 0.6 & 0.13 & 1 \\
\hline NSB & 0.29 & 0.61 & 0.54 & 0.59 & 0.56 & 0.35 \\
\hline
\end{tabular}

Source: Authoring

Table 4

The correlation matrix for the second step

\begin{tabular}{llllll}
\hline Parameter & $u_{16}$ & $u_{2}$ & $u_{3}$ & $u_{4}$ & $u_{5}$ \\
\hline$u_{2}$ & 0.24 & 1 & $\cdots$ & $\cdots$ & $\ldots$ \\
\hline$u_{3}$ & 0.74 & 0.42 & 1 & $\cdots$ & $\ldots$ \\
\hline$u_{4}$ & 0.59 & 0.54 & 0.74 & 1 & $\ldots$ \\
\hline$u_{5}$ & 0.08 & 0.46 & 0.26 & 0.39 & 1 \\
\hline$u_{7}$ & 0.32 & 0.61 & 0.54 & 0.59 & 0.56 \\
\hline
\end{tabular}

Source: Authoring 


\section{Table 5}

Estimated parameters of pair copulae of the hierarchical model

\begin{tabular}{llll}
\hline Copula & \multicolumn{2}{l}{ Alpha parameter } & Tau model value \\
\hline$u_{1}, u_{6}$ & $\alpha_{1}$ & 4.8416 & 0.7077 \\
\hline$u_{16}, u_{3}$ & $\alpha_{2}$ & 3.0958726 & 0.6075255 \\
\hline$u_{163}, u_{4}$ & $\alpha_{3}$ & 1.6051635 & 0.4452401 \\
\hline$u_{2}, u_{7}$ & $\alpha_{5}$ & 3.7974 & 0.655 \\
\hline$u_{1634}, u_{5}$ & $\alpha_{4}$ & 0.7117996 & 0.2624824 \\
\hline All & $\alpha_{4}$ & 0.7117996 & 0.2624824 \\
\hline
\end{tabular}

Source: Authoring

Table 6

The correlation matrix of the generated sample

\begin{tabular}{lllllll}
\hline Parameter & $u_{1}$ & $u_{2}$ & $u_{3}$ & $u_{4}$ & $u_{5}$ & $u_{6}$ \\
\hline$u_{2}$ & 0.02477 & 1 & 0.007165 & 0.164381 & 0.023541 & 0.060798 \\
\hline$u_{3}$ & 0.660594 & 0.007165 & 1 & 0.315456 & 0.223746 & 0.584442 \\
\hline$u_{4}$ & 0.350256 & 0.164381 & 0.315455 & 1 & 0.170522 & 0.360901 \\
\hline$u_{5}$ & 0.285568 & 0.023541 & 0.223746 & 0.170522 & 1 & 0.321597 \\
\hline$u_{6}$ & 0.710133 & 0.060798 & 0.584442 & 0.360901 & 0.321597 & 1 \\
\hline$u_{7}$ & -0.11607 & 0.470215 & -0.15824 & 0.111975 & 0.004708 & -0.04156 \\
\hline
\end{tabular}

Source: Authoring

\section{Table 7}

An analysis of the efficiency of a bank reserve for losses

\begin{tabular}{|c|c|c|c|c|c|c|c|c|}
\hline \multicolumn{2}{|l|}{ Indicator } & $A L P$ & VTB & PSB & PKB & KMB & $S I B$ & NMB \\
\hline \multicolumn{2}{|l|}{ Real value of overdue debt } & 0.037 & 0.055 & 0.037 & 0.087 & 0.021 & 0.073 & 0.054 \\
\hline \multicolumn{2}{|c|}{$\begin{array}{l}\text { Real value of the provision for unforeseen loan } \\
\text { losses }\end{array}$} & 0.076 & 0.077 & 0.055 & 0.134 & 0.061 & 0.164 & 0.089 \\
\hline \multirow{2}{*}{$\begin{array}{l}\text { Projected estimate of overdue } \\
\text { debt }\end{array}$} & Separate & 0.141 & 0.067 & 0.104 & 0.144 & 0.027 & 0.247 & 0.203 \\
\hline & Total & 0.052 & 0.071 & 0.051 & 0.124 & 0.028 & 0.156 & 0.176 \\
\hline
\end{tabular}

Note. Indicators are expressed in relative values.

Source:Authoring 


\section{Figure 1}

The histogram of the primary selection of the copula parameter

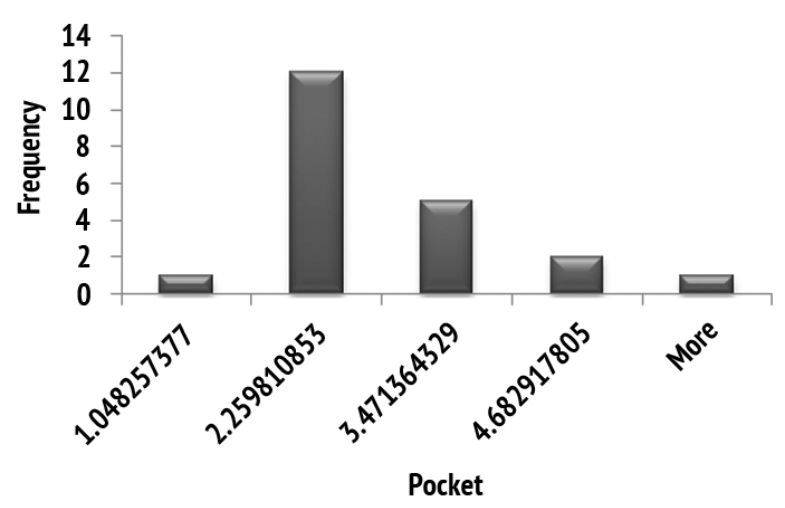

Source:Authoring

\section{Figure 2}

Hierarchical structure of the model

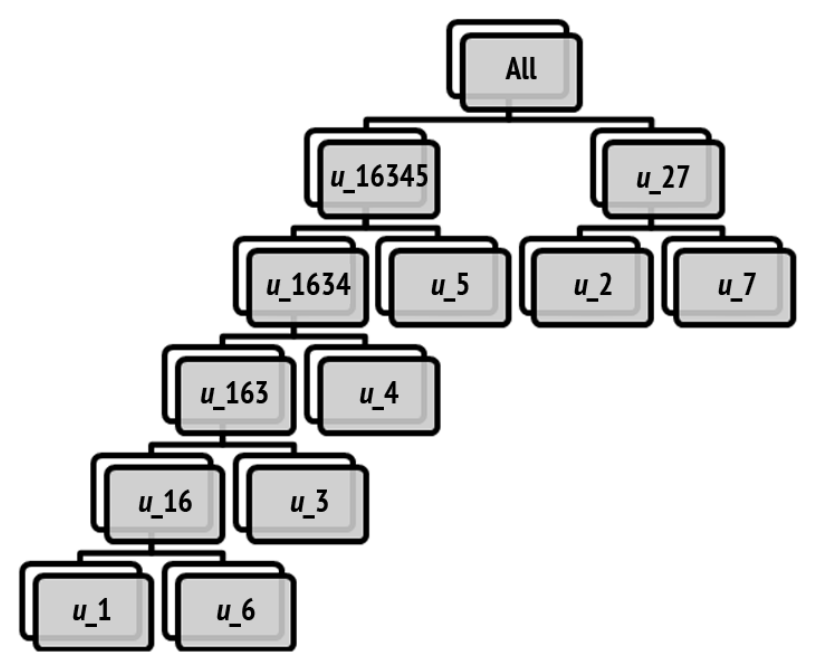

Source: Authoring

Please cite this article as: Kazakova K.A., Knyazev A.G., Lepekhin 0.A. Hierarchical Copulae in Credit Risk Modeling. Digest Finance, 2017, vol. 22, iss. 3, pp. 310-320. 


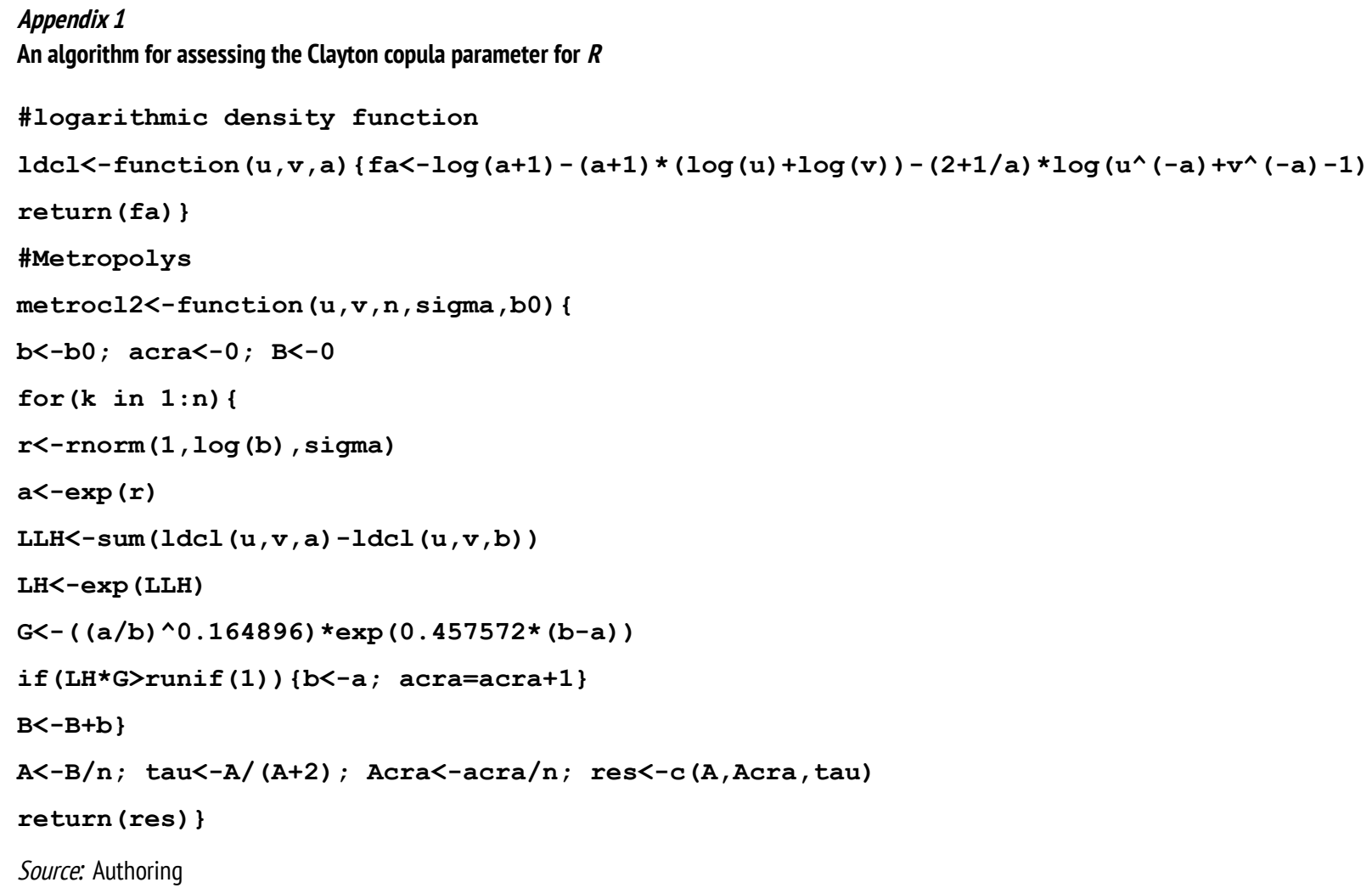

\section{References}

1. Bologov Ya.V. Otsenka riska kreditnogo portfelya s ispol'zovaniem kopula-funktsii [Assessing the risk exposure of the credit portfolio using the copula function]. Moscow, Sinergiya Press Publ., 2013, 22 p.

2. Fantazzini D. [Credit risk management]. Prikladnaya ekonometrika = Applied Econometrics, 2008, vol. 12, iss. 4, pp. 84-137. (In Russ.)

3. Fantazzini D. [An econometric analysis of financial data in risk management]. Prikladnaya ekonometrika = Applied Econometrics, 2008, vol. 10, iss. 2, pp. 105-138. (In Russ.)

4. Fantazzini D. [Modeling of multidimensional probability distributions with copula functions]. Prikladnaya ekonometrika = Applied Econometrics, 2011, vol. 2, iss. 2, pp. 98-134. (In Russ.)

5. Nelsen R.B. An Introduction to Copulas. New York, Springer, 2006, 269 p.

6. Aas K., Czado C., Frigessi A., Bakken H. Pair-Copula Constructions of Multiple Dependence. Insurance: Mathematics and Economics, 2009, vol. 44, iss. 2, pp. 182-198.

URL: https://doi.org/10.1016/j.insmatheco.2007.02.001

7. Czado C., Brechmann E.C., Gruber L. Selection of Vine Copulas. In: Copulae in Mathematical and Quantitative Finance. Springer-Verlag Berlin Heidelberg, 2013.

8. Travkin A.I. [Designing paired-copula constructs on the basis of empirical tails of copula: Evidence from the Russian market of shares]. XV Aprel'skaya mezhdunarodnaya nauchnaya konferentsiya po problemam razvitiya ekonomiki i obshchestva: materialy konferentsii [Proc. Sci. Conf. The 15th April International Scientific 
Conference on Development Issues of the Economy and Society]. Moscow, NRU HSE Publ., 2015, vol. 1, pp. 387-400.

9. Hering C., Hofert M., Mai J.-F., Scherer M. Constructing Nested Archimedean Copulas with Lévy Subordinators. Journal of Multivariate Analysis, 2010, vol. 101, iss. 6, pp. 1428-1433. URL: https://doi.org/10.1016/j.jmva.2009.10.005

10. Hofert M., Scherer M. CDO Pricing with Nested Archimedean Copulas. Quantitative Finance, 2011, vol. 11, iss. 5, pp. 775-787.URL: http://dx.doi.org/10.1080/14697680903508479

11. Hofert M., Mächler M., McNeil A.J. Archimedean Copulas in High Dimensions: Estimators and Numerical Challenges Motivated by Financial Applications. Journal de la Société Française de Statistique, 2013, vol. 154, iss. 1, pp. 25-63.

12. Hansen B.E. Autoregressive Conditional Density Estimation. International Economic Review, 1994, vol. 35, iss. 3, pp. 705-730.

13. Bolstad W.M. Introduction to Bayesian Statistics: Second Edition. John Wiley \& Sons, 2007, 464 p.

\section{Conflict-of-interest notification}

We, the authors of this article, bindingly and explicitly declare of the partial and total lack of actual or potential conflict of interest with any other third party whatsoever, which may arise as a result of the publication of this article. This statement relates to the study, data collection and interpretation, writing and preparation of the article, and the decision to submit the manuscript for publication. 